\title{
Long- and Short-Term Monocular Deprivation in the Rhesus Monkey: Effects on Visual Fields and Optokinetic Nystagmus
}

\author{
David L. Sparks, L. E. Mays, M. R. Gurski, and T. L. Hickey \\ Department of Physiology and Biophysics, Neurosciences Program, and Department of Physiological Optics, \\ University of Alabama at Birmingham, Birmingham, Alabama 35294
}

Monkeys with 1 eyelid sutured within 2 weeks of birth for 7 or $14 \mathrm{~d}$ (short-term monocular deprivation, $n=5$ ) or for 18-26 months (long-term monocular deprivation, $n=5$ ) were tested for visual and oculomotor function at approximately 2 years of age. Long-term monocularly deprived animals were behaviorally blind when visual inputs were restricted to the deprived eye. There was no sparing of the monocular segment of the visual field, and optokinetic nystagmus could not be elicited even with vertical stripes up to $15^{\circ}$ in width. These behavioral deficits could not be accounted for by optical or retinal abnormalities.

In contrast, short-term monocularly deprived animals displayed normal visual fields and optokinetic nystagmus was driven by both eyes. Slow-phase gain was reduced and directional asymmetries were observed when optokinetic stimulation was restricted to the deprived eye.

Restricted sensory stimulation during postnatal development can disrupt the normal maturation of neural circuits mediating sensory-guided behavior. For example, prevention of patterned visual inputs by suturing one eyelid for brief postnatal periods produces profound behavioral deficits when visual stimulation is later restricted to the deprived eye. Deficiencies in visuomotor coordination (Ganz and Fitch, 1968; Hoffmann, 1979; Sherman, 1973; Van Hof-Van Duin, 1978) and the spatial and temporal resolution of visual stimuli (Boltz et al., 1979; Harwerth et al., 1981; Hendrickson et al., 1977; von Noorden et al., 1970) have been demonstrated.

Alterations in the physiological properties of neurons in the visual pathways accompany these behavioral deficits - see Sherman and Spear (1982) for a recent review. Y cells are rarely encountered in the binocular segment of laminae of the lateral geniculate nucleus-receiving inputs from the deprived eye (Sherman et al., 1972, 1975; Zetlan et al., 1981). Those that are encountered have abnormal receptive fields and show reduced responsiveness to visual stimuli (Eysel et al., 1979; Hoffmann and Hollander, 1978; Kratz et al., 1978). Similarly, the functional organization (Hoffmann and Cynader, 1977; Hubel et al., 1976; Kratz et al., 1976; Shatz and Stryker, 1978; Singer, 1977; Spear et al., 1980; Wiesel and Hubel, 1965; Wilson and Sherman, 1977) and physiological properties (Baker et al., 1974; Crawford, 1978; Crawford et al., 1975; Wiesel and Hubel, 1963) of cells in the visual cortex are disrupted by brief periods of monocular deprivation.

Information gained from animal studies has important clin-

\footnotetext{
Received Aug. 26, 1985; revised Nov. 18, 1985; accepted Nov. 19, 1985.

We thank Richard Sheetz and Kathy Pearson for programming support and Isabel Ragland for invaluable technical assistance. This work was supported by NIH Grants R01EY02293 and P30EY03039.

Correspondence should be addressed to Dr. Sparks, Department of Physiology and Biophysics, University of Alabama at Birmingham, University Station, Birmingham, AL 35294.
}

Copyright $@ 1986$ Society for Neuroscience $0270-6474 / 86 / 061771-10 \$ 02.00 / 0$ ical implications. In humans, early stimulus deprivation (e.g., congenital cataracts or ptosis) is associated with amblyopia, a loss of vision that cannot be corrected optically. Sensory losses include reduced acuity (Hess et al., 1980; Sireteanu and Fronius, 1981; von Noorden and Burian, 1959a, b), lower contrast sensitivity (Gstalder and Green, 1971; Hess and Howell, 1977; Levi and Harwerth, 1977, 1980), poor temporal resolution (Hess et al., 1978; Manny and Levi, 1982a, b; Rentschler et al., 1981; Schor and Levi, 1980a; Wesson and Loop, 1982), disruptions of binocular vision (Hess, 1978; Levi et al., 1979; Sireteanu et al., 1981), and a variety of perceptual anomalies (Hess and Bradley, 1980; Hess et al., 1978). Oculomotor deficits also occur. Saccades to visual targets viewed through the amblyopic eye are hypometric and variable in amplitude (Ciuffreda et al., 1978; Schor, 1975). Deficits in the stability of fixation (Ciuffreda et al., 1980; Flom et al., 1980; Schor, 1975; Schor and Hallmark, 1978; von Noorden and Burian, 1958) and in the response to pursuit (Ciuffreda et al., 1979; Schor, 1975), vergence (Kenyon et al., 1981), and optokinetic (Schor and Levi, 1980b) stimuli have been reported.

The rhesus monkey, which has visual and oculomotor systems remarkably similar to those of the human, could serve as an animal model for studying the neuronal basis of amblyopia if manipulations can be found that produce similar sensory and motor abnormalities. However, relatively little is known about the effects of early deprivation on the visual and oculomotor systems of the monkey. For this reason we conducted a series of experiments examining the effects of long- and short-term monocular lid suture in the rhesus monkey. In this paper we describe the ability of monocularly deprived (MD) monkeys to orient to stimuli presented in various parts of the visual field and to respond to optokinetic stimuli. Future papers will describe the effects of long- and short-term monocular deprivation on other oculomotor functions, as well as neurophysiological and anatomical correlates of the visual and oculomotor deficits. Some of these results have been presented in abstract form (Sparks et al., 1982a, b).

\section{Materials and Methods}

\section{Subjects and general procedures}

This report is based on findings obtained from 1 normal and $10 \mathrm{MD}$ rhesus monkeys (Macaca mulatta). The MD monkeys were supplied by Litton Bionetics (Kensington, MD). Lids of all MD monkeys were sutured between 8 and $14 \mathrm{~d}$ of age and remained closed for either 7 or 14 $\mathrm{d}$ for the short-term MD animals $(n=5)$ and for 18-26 months for the long-term MD animals $(n=5)$. Postoperatively, animals were checked daily for signs of infection or lid openings, but no problems of this sort were encountered. The age at the time of lid suturing and the period of lid closure for each animal are given in Table 1 . Monkeys were maintained in a normal animal colony environment until they were transferred to the University of Alabama at Birmingham at approximately 18 months of age. After a quarantine period of at least a month, each. 
Table 1. Lid closure and refractive error in MD monkeys

\begin{tabular}{lllc} 
Monkey & $\begin{array}{l}\text { Age at } \\
\text { closure } \\
\text { (d) }\end{array}$ & Duration & $\begin{array}{l}\text { Refractive } \\
\text { error, de- } \\
\text { prived eye } \\
\text { (diopters) }\end{array}$ \\
\hline M-91 & 12 & 18 months & -3.00 \\
8391 & 12 & 24 months & -4.00 \\
8430 & 14 & 19 months & - \\
8431 & 14 & 21 months & -10.00 \\
8583 & 13 & 26 months & -0.50 \\
8884 & 14 & 42 months & -9.00 \\
9497 & 14 & $14 \mathrm{~d}$ & +0.50 \\
9520 & 14 & $7 \mathrm{~d}$ & - \\
9546 & 14 & $7 \mathrm{~d}$ & -1.25 \\
9802 & 8 & $14 \mathrm{~d}$ & +1.75 \\
9809 & 8 & $7 \mathrm{~d}$ & +0.50
\end{tabular}

animal received a head holder and eye coil implant (see below). On recovery from the surgical procedures, animals were trained on a saccadic tracking task and on a separate task used for plotting monocular and binocular visual fields. Short-term animals were also trained on a smooth pursuit tracking task. On completion of preliminary training, the sutured eye of the long-term MD animals was opened and formal testing of oculomotor capabilities (OKN, pursuit, saccades) and visual field measurements began. Both eyes of short-term MD animals were open during preliminary training.

\section{Surgical procedures}

The lid suturing procedure was similar to that described by von Noorden et al. (1970). The margins of the upper and lower eyelids were trimmed and the skin of each eyelid separated from underlying cartilage. Then, the cartilage of the lower lid was sutured to the skin of the upper lid and the edge of the upper lid was sutured to the skin of the lower lid.

Prior to behavioral training, each animal underwent two additional sterile surgical procedures under sodium pentobarbital anesthesia. In the first procedure, four stainless steel bolts were implanted into the skull, and a lightweight aluminum frame (used to immobilize the head) was later attached to the bolts. In some animals, a stainless steel post was secured to the skull using small stainless steel screws and dental cement. In the second procedure, a coil of fine wire was implanted beneath the insertions of the 4 recti muscles $(n=4)$ (Fuchs and Robinson, 1966) or, in some monkeys $(n=7)$, a prefabricated coil (Judge et al., 1980) was sutured to the sclera. The coil was attached to the nondeprived eye of 1 long-term MD animal. Coils were implanted in both eyes of the remaining subjects.

\section{Measurement of eye position}

Eye-position signals were obtained using the search coil magnetic-field method (Fuchs and Robinson, 1966). The alternating magnetic fields were produced by 6-foot-diameter coils surrounding the $O K N$ and visual field test apparatus. Horizontal and vertical eye position signals were obtained with a resolution of at least one-quarter of a degree.

\section{Visual field test apparatus}

One-half of a hollow sphere with a radius of $78 \mathrm{~cm}$ was painted matte black and placed inside the 6 -foot-diameter magnetic field coils. A $5 \times$ 5 array of red light-emitting diodes (LEDs), with $1^{\circ}$ spacing, was located at the center of the perimeter. Each of these 25 red LEDs could serve as fixation targets. Peripheral targets were 625 additional green LEDs separated in elevation and azimuth by $5^{\circ}$. The luminance of the LEDs was $1 \mathrm{~cd} / \mathrm{m}^{2}$. Although the peripheral targets were spaced at $5^{\circ}$ intervals, the fixation position could be varied in $1^{\circ}$ increments over a $5^{\circ}$ range. This permitted any selected region of the visual field to be plotted with a $1^{\circ}$ resolution.

Because the output of the eye position detection system becomes increasingly nonlinear as the eyes deviate from the magnetic axes of the coils, all testing was done within $45^{\circ}$ of the magnetic axes. This was accomplished by placing 4 additional $5 \times 5$ arrays of red LEDs $45^{\circ}$ above, below, and to the left and right of the center array. Thus, points in the right half of the visual field with eccentricities greater than $45^{\circ}$ were tested while the animal was fixating targets $45^{\circ}$ to the left of center.

\section{Behavioral methods for visual field plots}

Visual field plots were based on orienting responses. Animals were placed at the center of the sphere in a special restraining chair that permitted a clear view of the entire perimeter. In order to test the boundaries of the visual field, the head was not restrained; animals oriented to peripheral targets using a combination of eye and head movements. The water-delivery tube was attached to the animal's head so that the view of the visual field targets was not obstructed. This allowed delivery of the water reinforcement with the head in any position. The search coil method provided good resolution of gaze angle despite small errors resulting from translational movements of the head.

Long-term deprived monkeys were given extensive training on the visual field task before the deprived eye was opened. Then, the deprived eye was opened, and after several weeks of additional training, animals were tested both monocularly and binocularly on the task. Short-term MD monkeys were trained while viewing the targets binocularly and were tested under both monocular and binocular conditions.

Each trial began with an alerting tone. After 2 sec a center fixation LED was illuminated, and the animal was permitted $500 \mathrm{msec}$ to look to it. "On target" was defined by comparing gaze position to horizontal and vertical voltage windows. If the fixation stimulus was not acquired within $500 \mathrm{msec}$, or if fixation was not maintained for the required time, the trial was aborted and a new trial was initiated after a longer than normal delay. The center-fixation LED remained on for a variable interval (2-4 sec) during $25 \%$ of the trials, fixation (F) trials, and the animal was reinforced on a variable ratio schedule for maintaining fixation. These trials were inserted to prevent the animal from making intermittent searching eye and head movements to other parts of the visual field while the fixation stimulus was present. During the remainder of the trials, orienting $(\mathrm{O})$ trials, a second LED was illuminated for $2 \mathrm{sec}$ while the animal's gaze was directed at the center fixation LED. If the animal oriented to the peripheral stimulus, reinforcement was delivered on a continuous ratio schedule. On all $O$ trials, the centerfixation stimulus remained on until the orienting stimulus was extinguished.

As a consequence of this procedure, on $\mathrm{O}$ trials in which the peripheral stimulus was undetected, the animal maintained fixation of the center LED but was not reinforced for maintaining fixation. But because of the variable ratio schedule of reinforcement on fixation trials, this appeared to the animal as an unrewarded $F$ trial. Stimuli falling in the blind spot served as a control for this procedure. It was necessary to maintain the ratio of detectable to nondetectable trials at a fairly high level in order to maintain the animal's performance and to prevent the stress that accompanies prolonged performance on difficult tasks.

\section{Optokinetic nystagmus}

Monkeys were seated within a cloth drum $90 \mathrm{~cm}$ in diameter; the drum could be rotated in either direction in the horizontal plane at velocities up to $50 \% \mathrm{sec}$. The interior of the drum consisted of alternating blackand-white vertical stripes, the width of which could be changed. The drum was illuminated by a $40 \mathrm{~W}$ incandescent bulb mounted at the base of the drum. The luminance of the black-and-white stripes was 0.5 and $4.5 \mathrm{~cd} / \mathrm{m}^{2}$, respectively.

Horizontal and vertical eye position signals of both eyes were sampled at $500 \mathrm{~Hz}$ and stored on digital magnetic tape during a number of discrete OKN trials. Subsequent analysis revealed that all optokinetic eye movements were conjugate. Thus, the average velocity of each slowphase movement of the nondeprived eye was computed and used as a single index of optokinetic responses. Each trial was divided into two segments: a 1 min record with full illumination and drum rotation; and $30 \mathrm{sec}$ of optokinetic afternystagmus (OKAN) obtained in complete darkness and the drum stationary. In order to maintain alertness, 4 of the 5 short-term MD animals received $0.25 \mathrm{mg} / \mathrm{kg}$ of $d$-amphetamine before OKN testing began.

Because of an instrumentation failure, the gain of optokinetic responses mediated by the nondeprived eye of the long-term MD animals could not be determined precisely. After these animals were sacrificed, a $10-15 \%$ variation between the selected and actual drum speed was discovered. In experiments with the short-term MD animals, this problem was corrected and, additionally, a record of actual drum speed was preserved along with the eye-movement data. 


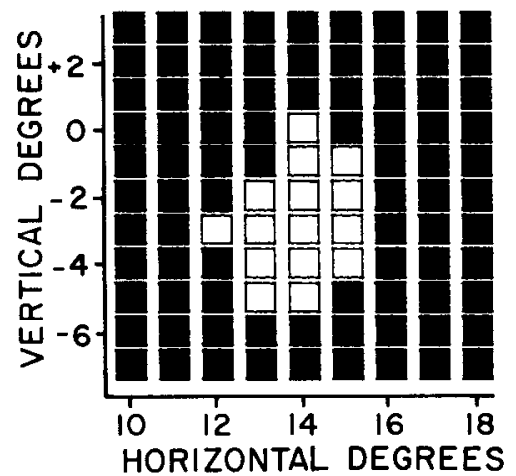

Figure 1. Plot of the blind spot of a normal monkey. Each square represents a tested point. Filled squares represent points detected 5 or more times in 9 presentations. Unfilled squares represent points detected 4 or fewer times in 9 presentations. Animals oriented reliably to visible targets but maintained fixation of the center target when nonvisible targets were presented.

\section{Results}

\section{Informal testing}

\section{Long-term MD animals}

When visual input was restricted to the deprived cyc, long-term MD monkeys appeared to be behaviorally blind. Oculomotor, limb, or bodily movements could not be elicited by moving or stationary visual stimuli (food objects, water bottles, threat stimuli, etc.) presented in any part of the visual field. Stimulation of either the nondeprived or deprived eye produced consensual pupillary reflexes. Measurements of eye alignment obtained by a corneal reflection method indicated that none of the animals were strabismic.

The total lack of responsiveness to visual stimulation of the deprived eye could not be accounted for by optical or retinal deficits. The estimates of refractive error obtained by streak retinoscopy are shown in Table 1 . Although the deprived eye was myopic in all long-term MD animals, this would not account for the total lack of response to visual stimuli. The fundi of the deprived eyes appeared normal. Neither retinal degeneration nor abnormalities associated with the optic disk were observed.

\section{Short-lerm MD anirnals}

In contrast to what was observed in the long-term MD animals, short-term MD animals did not appear to be behaviorally blind. Oculomotor, limb, and bodily movements could be elicited easily by moving or stationary visual stimuli presented in any part of the visual field. Stimulation of either the nondeprived or deprived eye produced consensual pupillary reflexes, and the fundi of the deprived eyes appeared normal. Estimates of refractive error obtained by streak retinoscopy are shown in Table 1. While all of the long-term MD animals were myopic, the short-term MD animals were either myopic or hyperopic. Eye alignment of all the short-term MD animals was normal.

\section{Visual field plots}

The use of an orienting response to map visual fields assumes that the monkey looks to visible targets and maintains fixation of the center target when nonvisible targets are presented. To test these assumptions, test stimuli were presented on and around the blind spot under monocular viewing conditions. Typical results are shown in Figure 1. Each square represents a tested point. Filled squares indicate target locations in which the targets were detected at least $5 \times$ in 9 presentations; unfilled squares represent target positions that were detected fewer than $5 \times$ in 9 presentations. Animals consistently failed to break fixation
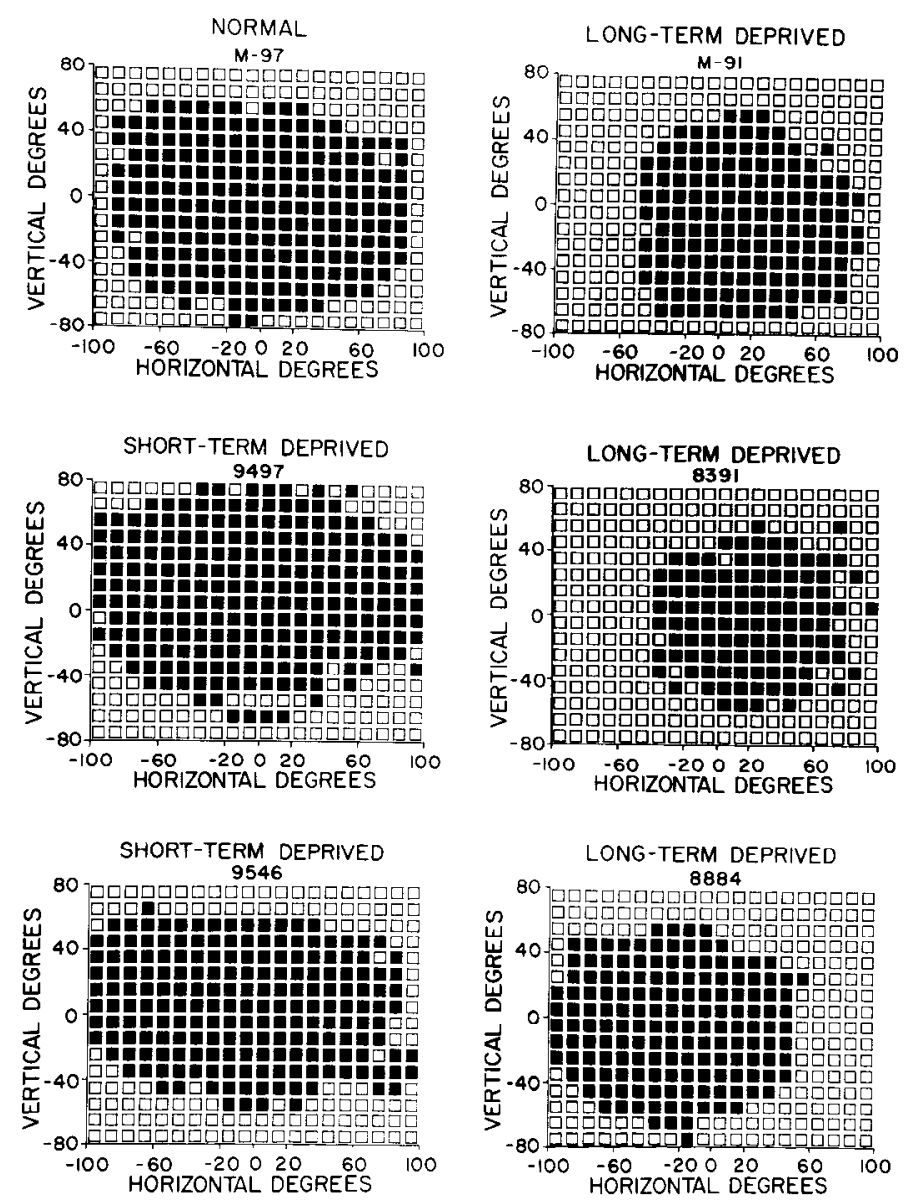

Figure 2. Binocular visual field plots of normal, long-term, and shortterm MD animals. As in Figure 1, filled and unfilled squares represent detected and nondetected tested points, respectively. Lid suture surgery was performed on the left eye of 3 animals (M-91, 8391, and 9497) and on the right eye of 2 animals (8884 and 9546). The binocular visual field plots of the short-term MD animals resembled that of the normal animal, while those of the long-term MD animals did not.

when targets could not be detected, yet reliably oriented to visible targets.

Figure 2 presents binocular visual field plots of 1 normal, 3 long-term MD, and 2 short-term MD animals. Although variable from animal to animal, the binocular visual fields of normal and short-term MD animals were similar (approximately 20,000 $\mathrm{deg}^{2}$ ) and extended $\pm 90^{\circ}$ horizontally and $\pm 60^{\circ}$ vertically. In contrast, the binocular visual fields of long-term MD animals were smaller (approximately 14,000 $\mathrm{deg}^{2}$ ), since they did not include the monocular segment of the deprived eye. This is illustrated in Figure 3, which compares the binocular and monocular fields of the nondeprived eye. The monocular field of the nondeprived eye and the binocular visual field were almost identical $\left(14,400\right.$ vs $14,700 \mathrm{deg}^{2}$ for M8884 and 14,200 vs 14,500 for M91), indicating that, under binocular viewing conditions, orienting responses were being mediated only by the nondeprived eye of the long-term MD animals. The failure of the deprived eye to mediate orienting responses was not unique to binocular viewing conditions. Orienting eye or head movements were not produced by visual stimuli presented to the deprived eye during test sessions in which the nondeprived eye was patched. Saccadic eye movements or head movements were not made in response to visual stimuli presented to only the deprived eye in either monocular or binocular viewing conditions. Thus, under these test conditions, animals were behaviorally 

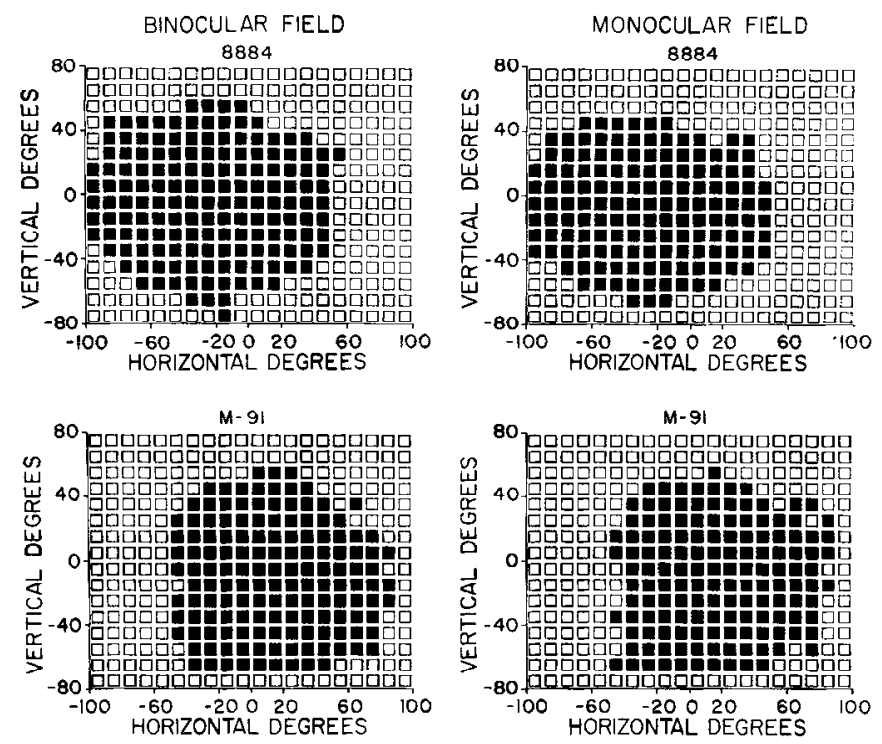

Figure 3. Binocular and monocular visual field plots of 2 long-term MD animals. One long-term animal was visually deprived in the right eye (8884), while the other animal was visually deprived in the left eye (M-91). Monocular visual field plots were obtained with the deprived eye patched; filled squares represent targets that were detected. Under binocular viewing conditions, no orienting responses were made to targets presented in the monocular visual field of the deprived eye. In each case, the binocular visual field plot resembled the monocular visual field plot of the nondeprived eye.

blind when visual input was restricted to the deprived eye. There was no evidence of sparing of the monocular segment of the visual field of the deprived eye.

In contrast to the long-term MD animals, orienting eye and head movements were observed when vision was restricted to the deprived eye of short-term MD animals. Normal monocular visual fields were obtained when vision was restricted to the deprived eye (Fig. 4). Furthermore, the binocular fields of the short-term MD animals are similar to those of normal animals (Figs. 2, 4). Visual field plots of the deprived eye were not obtained for 1 short-term MD animal that was unable to perform the behavioral task because of a marked instability in eye position when the nondeprived eye was patched.

\section{Optokinetic nystagmus}

Although long-term MD monkeys appeared to be behaviorally blind when vision was restricted to the deprived eye, subjects were also tested with optokinetic stimuli since responses to rotation of full-field stimuli are not dependent on learned behavioral responses.

Figure 5 illustrates data from a normal animal. While slight differences in the responses mediated by the 2 eyes are apparent at higher drum velocities, the gain and velocity of the slowphase response were relatively independent of the direction of drum rotation - nasal/temporal $(N / T)$ or temporal/nasal $(T / N)$.

When visual input was restricted to the deprived eye, 4 of the 5 long-term MD animals failed to produce optokinetic responses (Fig. 6). For these animals, optokinetic responses (OKN) were not present when the drum was rotated in either direction at velocities from $10^{\circ}-50^{\circ} / \mathrm{sec}$ and with stripes up to $15^{\circ}$ wide. Vigorous $\mathrm{OKN}$ responses were observed when the nondeprived eye was viewing the drum. One long-term MD animal showed some slight evidence of OKN when stimuli were presented to the deprived eye (Fig. 7). These responses were not due to light leakage, since the data shown were obtained with the nondeprived eye sutured and patched. However, even for this monkey,
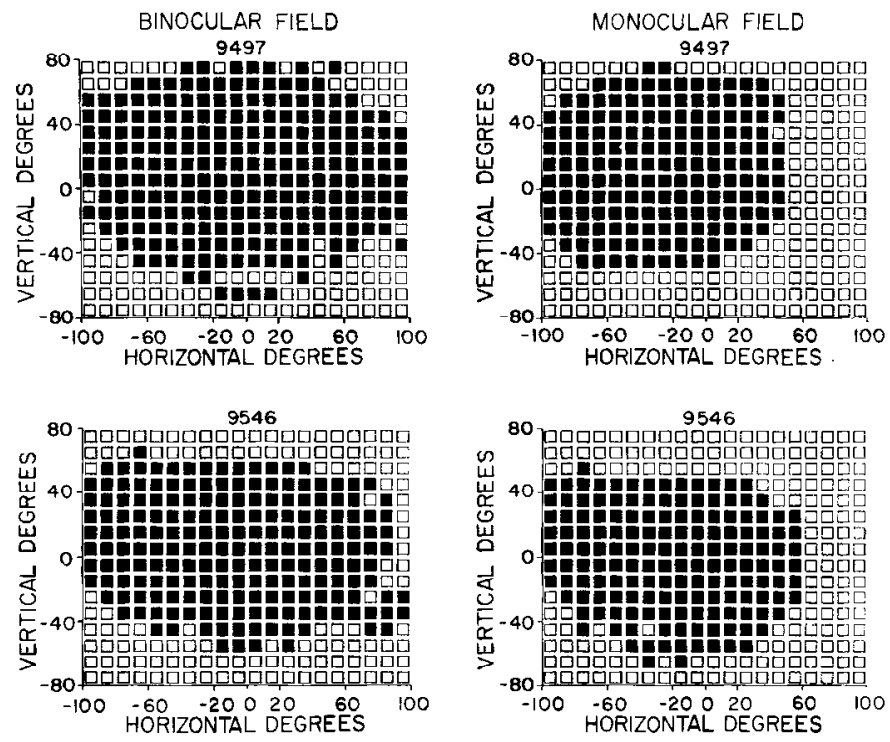

Figure 4. Binocular and monocular visual field plots of 2 short-term MD animals. The monocular visual field plot for 9497 was obtained when the animal was viewing the targets through the deprived eye; the monocular visual field plot for 9546 was obtained when the targets were viewed with the nondeprived eye. Both binocular visual field plots were similar to that of a normal animal. Also, the monocular visual field plots were similar when the targets were viewed with the deprived or nondeprived eye.

eye velocity did not exceed $8 \% \mathrm{sec}$ even with the drum rotating at $30^{\circ}$ or $50 \% / \mathrm{sec}$ in the $\mathrm{T} / \mathrm{N}$ direction, and there was no OKN with $\mathrm{N} / \mathrm{T}$ rotation at any drum velocity. With the nondeprived eye viewing, OKN performance was normal, except at rotations of $50 \% / \mathrm{sec}$, at which there was a higher gain associated with $\mathrm{N} / \mathrm{T}$ rotation.

In contrast to what was observed with the long-term MD monkeys, OKN responses were mediated by the deprived eye of all short-term MD monkeys under monocular viewing conditions. Data for animals with the best (Fig. 8), poorest (Fig. 10), and intermediate (Fig. 9) performances are shown. While drum rotation in either the $T / N$ or $N / T$ direction produced OKN, asymmetric responses were observed when stimulation was restricted to the deprived eye; eye velocity was higher with $\mathrm{T} / \mathrm{N}$ drum rotation. For 1 short-term MD animal, eye velocity during N/T rotation did not exceed $15 \%$ sec (Fig. 10).

When OKN stimuli were presented to the nondeprived eye, OKN gain was higher than when stimulation was restricted to the deprived eye, and symmetrical directional responses were observed. Additionally, asymptotic eye velocity was reached faster with the nondeprived eye (Figs. 8-10). Overall, OKN mediated by the nondeprived eye was similar to that observed in normal animals.

Optokinetic afternystagmus (OKAN) was not noticeably affected by short-term deprivation. While, for a particular drum velocity, the eye usually reached a lower steady-state velocity when the deprived eye was viewing, the time constant of the decay of OKAN was similar for the deprived and nondeprived eyes (Fig. 11).

\section{Discussion}

\section{Informal testing}

After long-term monocular deprivation, monkeys display profound deficits in visually guided behavior. In our experiments, monkeys reared for 18-26 months with one eyelid sutured appeared to be behaviorally blind when the nondeprived eye was 
10\%SEC

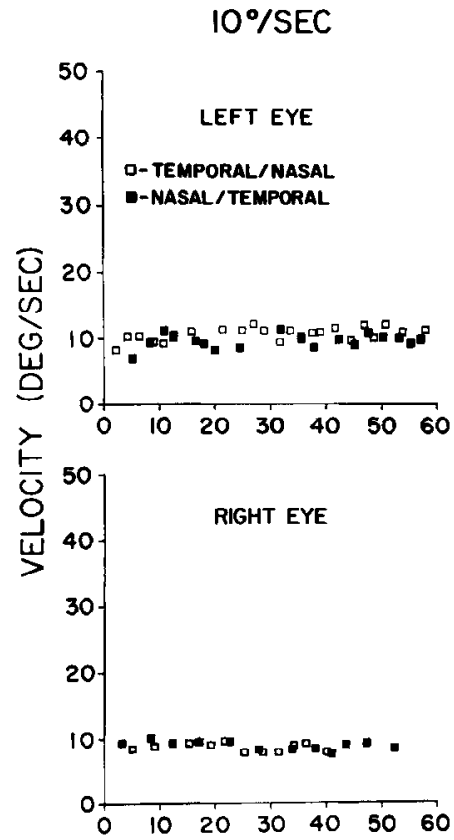

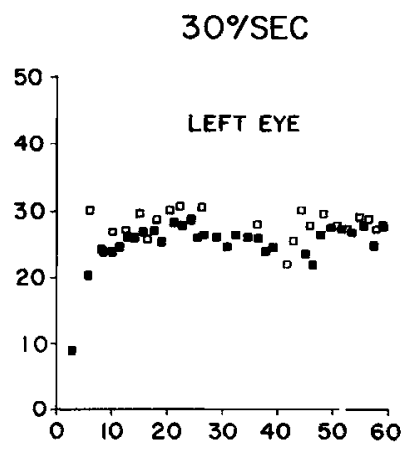

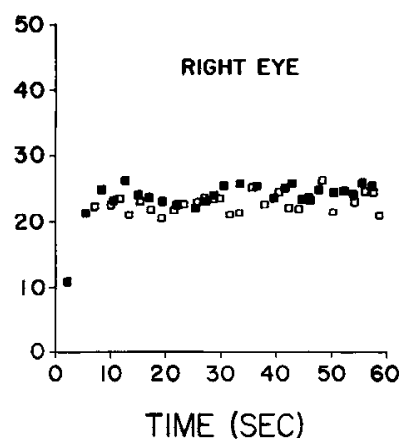

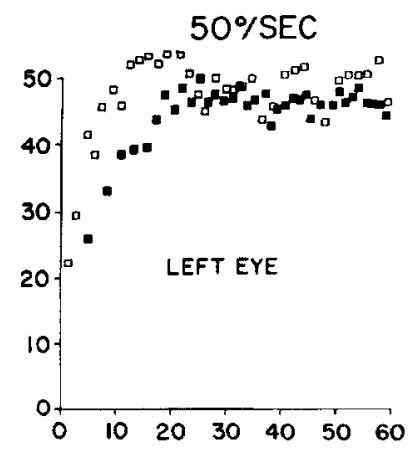

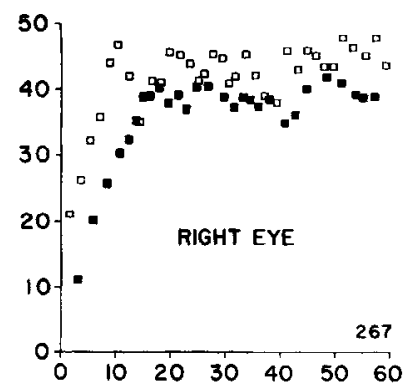

Figure 5. OKN plots obtained from a normal monkey. Plots, obtained under monocular viewing conditions, are of slow-phase velocity. In this and Figures 7-10, each symbol represents the average of 3 consecutive slowphase excursions. Drum rotation was in 2 different directions ( $T / N$ and $N / T$ ) at 3 different velocities $\left(10^{\circ}, 30^{\circ}\right.$, and $50 \% \mathrm{sec}$. Slow-phase gain was slightly greater when the left eye was open. patched. Except for 1 animal that showed weak OKN, a pupillary response to light was the only behavior that could be elicited by stimuli presented to the deprived eye. Optical abnormalities or retinal anomalies do not account for the observed behavioral deficits. No recovery of function was observed over the 12-24 months of testing. However, recovery is more likely to occur following reverse suture (i.e., opening the deprived eye and suturing the nondeprived eye). The experimental protocol in which each animal was tested on a variety of oculomotor tasks and also used for chronic single-unit recording experiments did not permit an assessment of recovery after reverse suture.

Our observations are consistent with results of previous investigations. Von Noorden et al. (1970) reported that monkeys with unilateral lid closure during the first 4 weeks of life were unable to perform an acuity task using the deprived eye. They observed no recovery after 6-24 months of reverse suture. Similarly, Baker et al. (1974) reported that monkeys reared with unilateral lid closure displayed only gross light perception. Hendrickson et al. (1977) reared one monkey in conditions similar to those of the present experiment. That animal had one eyelid sutured at 3 weeks of age. Immediately after a reverse suture at 9 months of age, little visually guided behavior was mediated by the deprived eye. After 2 or more weeks of reverse suture, the monkey began to orient to and follow lights and could retrieve raisins presented at random locations.

More recently, Harwerth et al. (1981) measured the contrast sensitivity of the nondeprived and deprived eyes of monkeys with one eyelid sutured at the age of 1 month for periods of 2 weeks, 19 months, and 23 months. The high spatial frequency cut-off in the contrast sensitivity plot was 6 octaves lower in the deprived eye for all 3 animals. For the 2 long-term MD animals, profound deficits were observed in the incrementthreshold spectral sensitivity of the deprived eye and the darkadapted threshold for detection of large test fields was 3-4 log units higher in the deprived eye.

In contrast to the long-term MD animals, our informal tests failed to reveal deficits of visually guided behavior in the shortterm MD animals.

\section{Visual field plots}

If kittens reared with 1 eye sutured are tested with the deprived eye, orienting responses are made only to visual stimuli presented in the monocular segment of the visual field (Sherman, 1973, 1974). The loss of orienting responses to stimuli in the binocular segment of the visual field is associated with a reduction in cell size of the binocular regions of laminae receiving input from the deprived eye (Guillery, 1972; Guillery and Stelzner, 1970) and with a reduction in the size of deprived eye ocular dominance columns in the visual cortex (Wiesel and Hubel, 1963, 1965; Wilson and Sherman, 1977). The reduction of cell size in the binocular segment of the lateral geniculate nucleus without a corresponding reduction in the monocular segment has been attributed to a competitive interaction between the retinogeniculocortical pathways for the 2 eyes. It is hypothesized that axons from the lateral geniculate nucleus conveying signals from the deprived eye are at a disadvantage in the visual cortex, where they must compete for synaptic space with afferents from the nondeprived eye. Presumably, there is no competition among

A

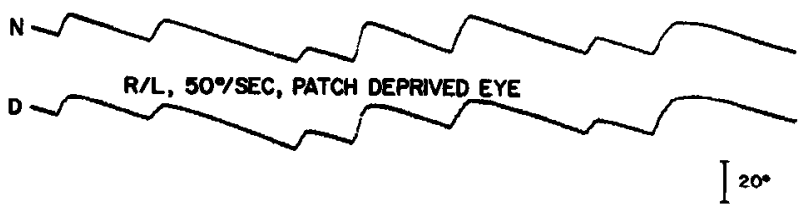

B

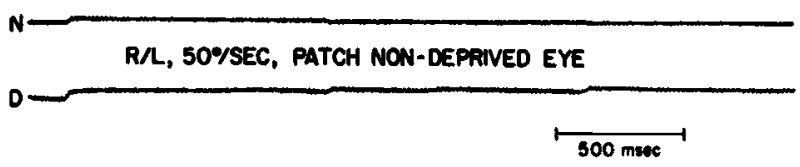

Figure 6. Horizontal eye position signals of nondeprived $(N)$ and deprived $(D)$ eyes of a long-term animal during rotation of optokinetic drum (alternating black and white stripes $15^{\circ}$ in width). $A$, Conjugate OKN responses with the nondeprived eye viewing. $B$. OKN was not observed when visual input was restricted to the deprived eye. 
Figure 7. OKN plots obtained from a long-term MD monkey. Stimulation of the deprived eye occurred while the nondeprived eye was sutured and patched. With stimulation restricted to the deprived eye, OKN could be obtained only with $\mathrm{T} / \mathrm{N}$ drum rotation. OKN through the nondeprived eye appeared to be normal, although the velocity of slow phases was higher with N/T rotation at $50 \%$ sec.
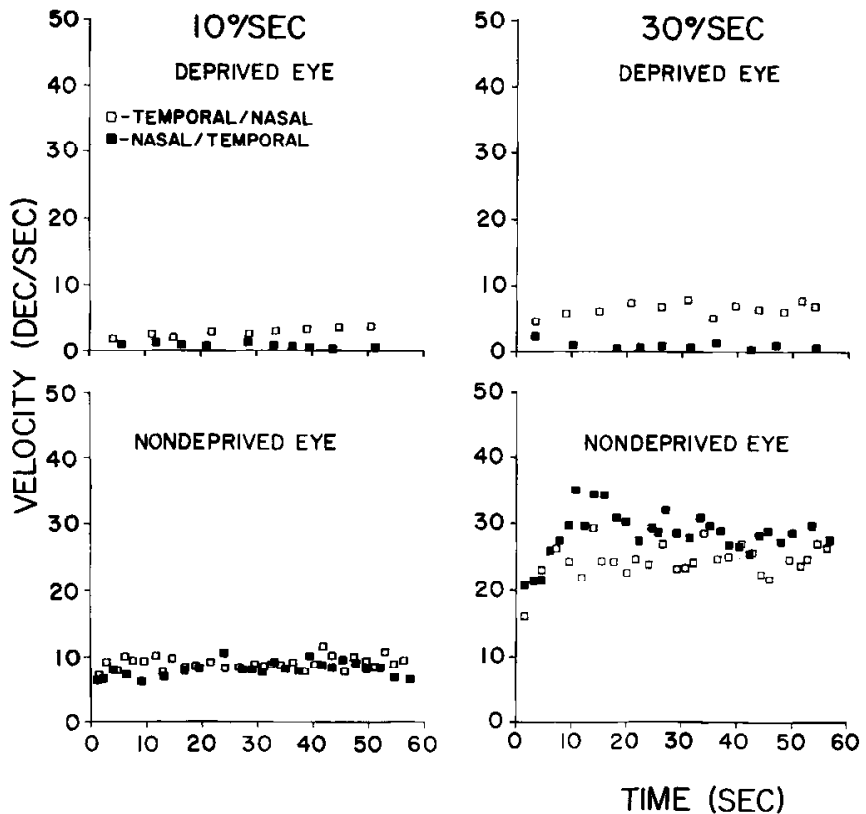

neurons representing monocular segments of the visual field, and regions of the visual cortex representing this part of the visual field are normal structurally.

The consequences of long-term monocular lid closure on the detectability of stimuli presented to various parts of the visual field in primates have received little experimental attention. Joseph and Casagrande (1980) measured the visual fields of prosimian primates (Galago crassicaudatus). After long-term monocular lid closure, the deprived eye was opened and the nondeprived eye sutured. Initially, all deprived animals behaved as if blind on perimetry and other visuomotor tests. Over the following 4-8 weeks, limited recovery on the visuomotor tasks was observed. During this period, perimetry testing showed that vision was limited to the deprived monocular segment. Thus, rearing of these primates with 1 eye sutured caused a severe reduction of vision in the binocular segment of the visual field while sparing vision in the monocular crescent. The only other report of the visual fields of monocularly deprived primates is that of Hendrickson et al. (1977). They report that when tested with the deprived eye alone, monkeys appear equally handicapped throughout the deprived field.

Unlike the observation in MD cats, we found no evidence that the monocular segment of the visual field of long-term MD monkeys was spared. Monkeys tested with only the deprived eye failed to orient to stimuli presented in any part of the visual field. Visual field plots of MD animals obtained with both eyes open were identical to the fields plotted when only the nondeprived eye was open. Thus, stimuli available to only the deprived eye were not used to control saccadic eye movements or head movements in our perimetry task.

This negative finding must be interpreted cautiously. It cannot be stated that these animals would be unable to detect stimuli
Figure 8. OKN plots obtained from a short-term MD monkey. With stimulation restricted to the deprived eye, slow-phase velocity was slightly asymmetrical and the build-up to asymptotic performance was slow, particularly at the higher drum velocities. For the nondeprived eye, slowphase velocity was independent of the direction of drum rotation and a rapid rise to steady-state performance was observed. The optokinetic responses of this animal were more similar to those of normal animals than any of the other short-term MD subjects.
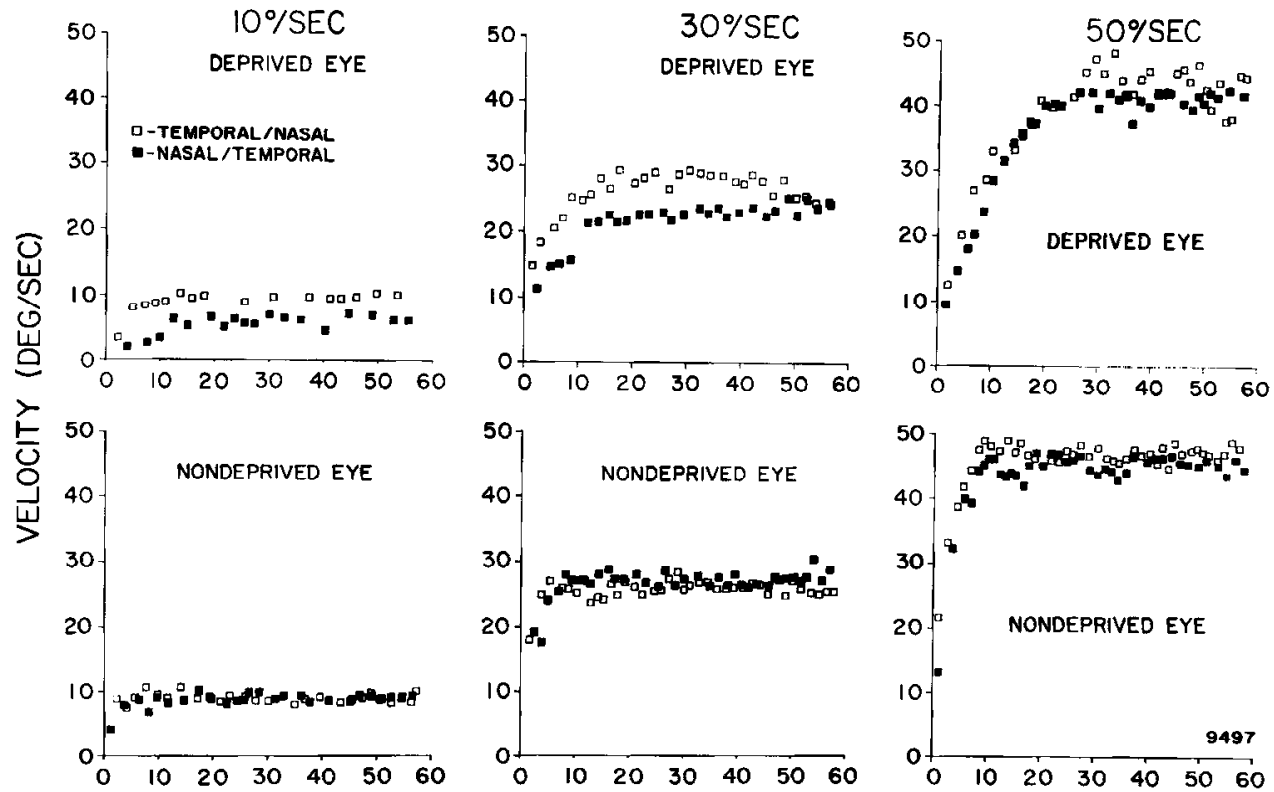

TIME (SEC) 

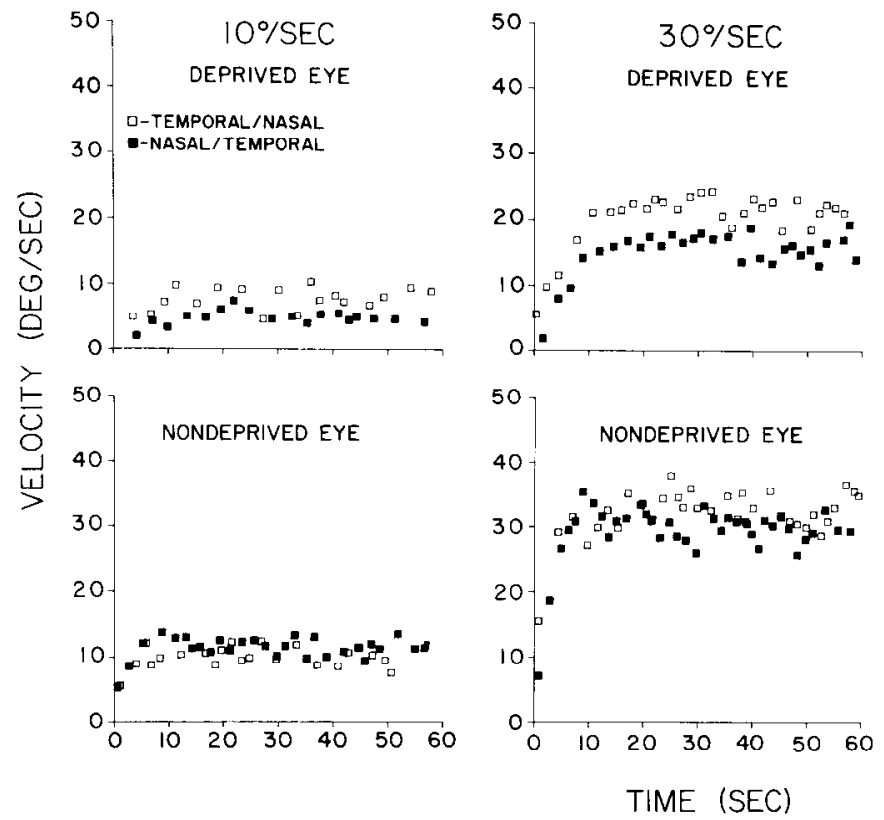

under other test conditions (e.g., using very bright flashes of light) or following extended periods of reverse suture (Blakemore et al., 1981; Hendrickson et al., 1977; Joseph and Casagrande, 1980). But we saw no evidence of sparing of the monocular visual field with informal testing using methods similar to those used in cats. In the perimetry task, in which stimuli were readily observed by normal monkeys and humans, orienting responses failed to occur, even in highly motivated subjects. Moreover, on some occasions we flashed or flickered the $5^{\circ} \times 5^{\circ}$ array of LEDs while the animal was fixating various single LEDs. Longterm monkeys did not orient to these compelling stimuli when only the deprived eye was stimulated.

In contrast to the findings in long-term MD monkeys, visual field deficits were not observed in short-term MD animals. The binocular visual field was unaffected. While this indicates that

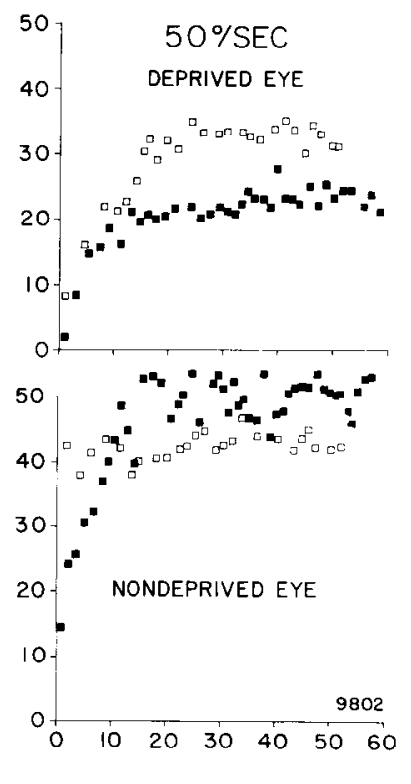

Figure 9. OKN plots obtained from a second short-term MD monkey. For the deprived eye, slow-phase velocity was higher with $\mathrm{T} / \mathrm{N}$ drum rotation than with $\mathrm{N} / \mathrm{T}$ rotation. Also, a slow buildup to asymptotic performance was associated with the higher drum velocities. For the nondeprived eye the slow-phase velocity was symmetrical at drum velocities of $10^{\circ}$ and $30^{\circ} \%$ sec. An asymmetrical response was obtained at $50 \%$ sec with a slightly higher slow-phase velocity associated with $\mathrm{N} / \mathrm{T}$ drum rotation. A short risetime to asymptotic performance was observed.

animals can detect stimuli at the intensity used at all locations, it should be noted that an increased threshold for detection has been observed for stimuli presented in the binocular region of the visual fields of human amblyopes (Moran and Gordon, 1982). Moreover, the orienting responses driven by the deprived eye had greater latency and reduced velocity. These and other effects of short-term monocular deprivation on the oculomotor system will be described in detail in a subsequent report.

\section{Optokinetic nystagmus}

\section{Observed deficits}

Except for 1 animal, long-term MD animals did not generate optokinetic responses when only the deprived eye was open. Rotation of the optokinetic drum in either direction (N/T or
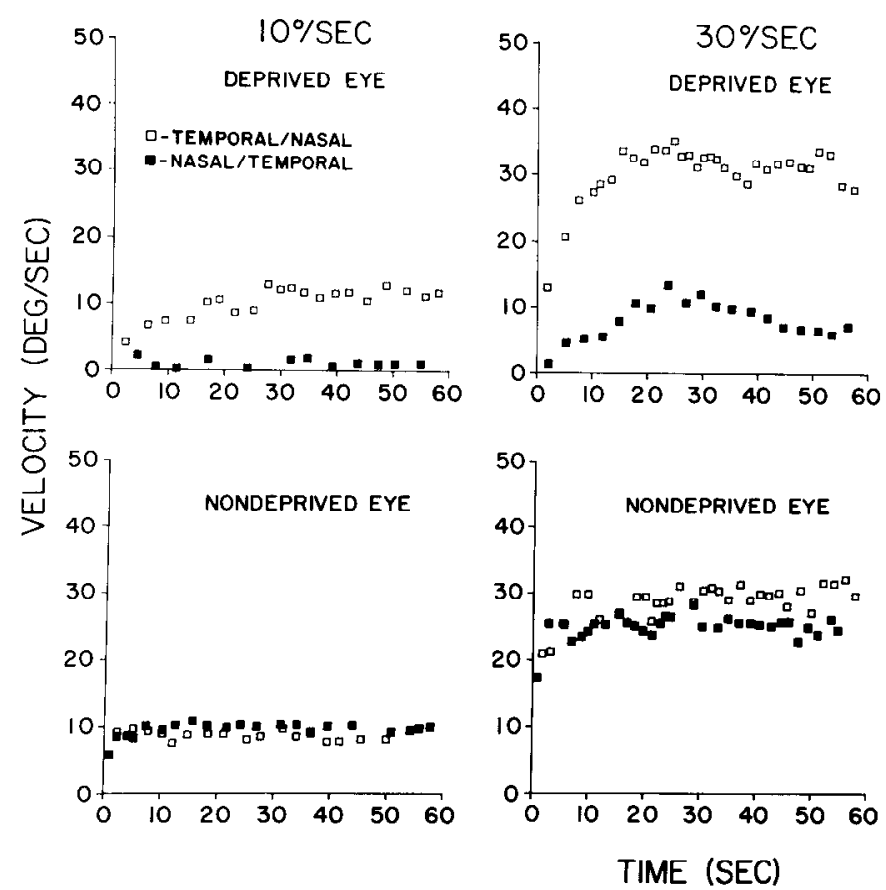
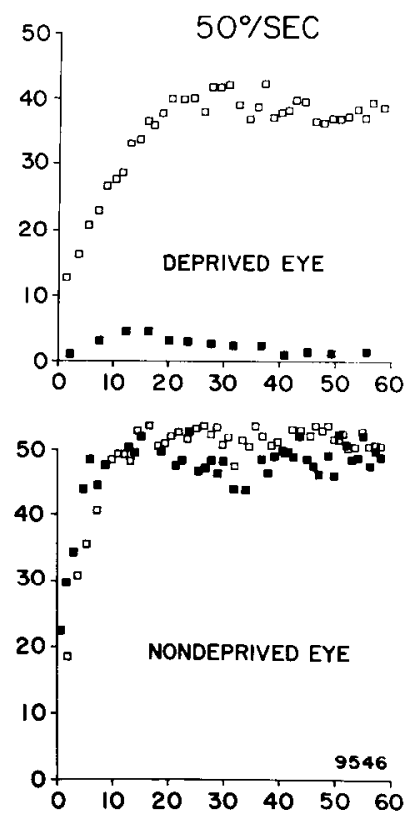

Figure 10. OKN plots obtained from a third short-term MD monkey. For the nondeprived eye, slow-phase velocity was independent of the direction of drum rotation and steady-state performance was quickly obtained With stimulation of the deprived eye, $\mathrm{T} / \mathrm{N}$ drum rotation was more effective than $\mathrm{N} / \mathrm{T}$ rotation in eliciting $\mathrm{OKN}$ responses. With N/T rotation, slowphase velocity never exceeded $10 \% \mathrm{sec}$. When vision was restricted to the deprived eye, the rise to asymptotic performance was slow. 


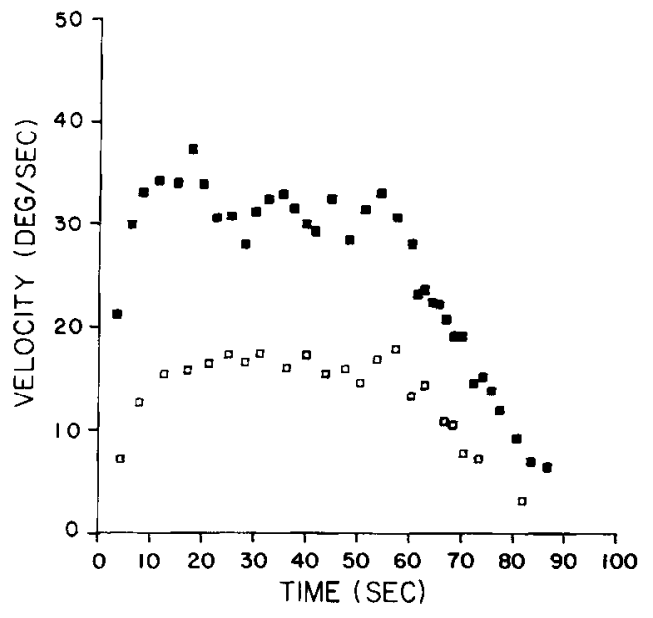

Figure 11. Plots of OKN and OKAN obtained from a short-term MD monkey with nondeprived (filled symbols) or deprived (unfilled symbols) viewing. The optokinetic drum was rotating nasotemporally at $30 \% / \mathrm{sec}$. After $60 \mathrm{sec}$, the animal was in total darkness and the drum was stationary.

$\mathrm{T} / \mathrm{N}$ ) at velocities from $10^{\circ}-50^{\circ} / \mathrm{sec}$ and with stripes up to $15^{\circ}$ in width failed to evoke optokinetic responses when visual input was restricted to the deprived eye. When the nondeprived eye was viewing the drum, optokinetic responses appeared normal.

One long-term MD monkey showed evidence of optokinetic responses when the deprived eye was viewing the drum. In this animal, optokinetic reponses were not observed when the drum was rotated in the $\mathrm{N} / \mathrm{T}$ direction. With $\mathrm{T} / \mathrm{N}$ rotation, slow-phase movements occurred, although eye velocity never exceeded $8^{\circ} \%$ sec even with a drum velocity of $50 \% \mathrm{sec}$.

Optokinetic responses were driven by the deprived eye of short-term MD animals. In general, the gain of optokinetic responses driven by the deprived eye was lower than the gain of the nondeprived eye. This was particularly true with higher drum velocities and for drum rotation in the $\mathrm{N} / \mathrm{T}$ direction. Also, with higher drum velocities, the time required to reach steady-state eye velocity was increased (Figs. 8-10).

\section{Buildup of OKN}

In normal animals, optokinetic nystagmus is composed of a rapid initial change in slow-phase eye velocity followed by a slower rise to a steady-state level (Cohen et al., 1977). The rapid rise in slow-phase velocity and the slower rise to a steady state are thought to be generated by separate neural processes. Patients with deficits in slow pursuit of visual targets and monkeys with lesions of the cerebellar flocculus (Waespe et al., 1983; Yee et al., 1979; Zee et al., 1981) display a gradual buildup of the slow phase of OKN. A velocity-storage mechanism shared with the vestibular system is hypothesized to be responsible for the slow buildup of slow-phase velocity and OKAN. Labyrinthectomy (Cohen et al., 1973; Zee et al., 1976) or other damage to vestibular pathways prevents the gradual build-up of slow-phase velocity and abolishes OKAN.

In our experiments, long-term monocular deprivation completely eliminated optokinetic responses when visual stimulation was restricted to the deprived eye. This is not a purely motor deficit, since normal optokinetic responses were evoked by stimulation of the nondeprived eye. Thus, the deficit must be due to the effects of long-term deprivation on sensory neurons sensitive to full-field visual stimulation, to a disruption of sensory-motor linkages, or to a combination of these effects.

Short-term monocular deprivation differentially affects the processes involved in optokinetic nystagmus. Neural circuits responsible for the rapid build-up of slow-phase eye velocity seem to be impaired, since asymptotic levels of slow-phase velocity were reached later when the deprived eye was viewing. The velocity-storage mechanism, responsible for the slow buildup of eye velocity and for OKAN, does not appear to be affected. The time constant of the decay of OKAN is similar in deprived and normal animals.

\section{Asymmetry of $O K N$}

Short-term monocular deprivation differentially affects optokinetic responses to N/T and T/N stimulation. Recent experiments have disclosed neural mechanisms possibly related to the observed asymmetry of optokinetic responses seen in MD animals. In the cat and afoveate mammals, neurons in the nucleus of the optic tract (NOT) in the pretectum are known to contribute significantly to slow-phase optokinetic movements (see Hoffmann, 1983; Precht, 1981; and Schor, 1983, for recent reviews). These neurons are sensitive to full-field visual stimulation, are directionally selective, and are tuned for the velocity of stimulus movement. In the cat, the NOT receives inputs directly from the retina as well as extensive projections from the cortex. Moreover, there is evidence to suggest that these different pathways are involved in encoding the velocity and direction of whole field stimuli moving in different directions across the retina. OKN responses evoked by full-field stimuli moving nasotemporally are markedly reduced after ablation of the visual cortex (Wood et al., 1973). Other evidence indicates that the cortical pathway also contributes to the optokinetic response to high-velocity stimuli moving temporonasally (Hoffman, 1981; Precht, 1981). Thus, the direct retinopretectal pathway may mediate $\mathrm{T} / \mathrm{N}$ optokinetic responses with low-velocity stimulation, while the indirect cortical pathway contributes to $\mathrm{N} / \mathrm{T}$ OKN and high-velocity $\mathrm{T} / \mathrm{N}$ responses. Recent data (Malach et al., 1984) indicate that, in the cat, long-term monocular deprivation severely disrupts cortical pathways mediating OKN while sparing subcortical OKN pathways. OKN responses driven by the nondeprived eye were severely disrupted by cortical lesions. OKN responses to temporalward stimulation of the deprived eye were virtually abolished by long-term monocular deprivation. However, the residual $\mathrm{OKN}$ responses were unaffected by cortical lesions.

Rclatively littlc is known about the neural circuits involved in OKN in the monkey (see Keller and Crandall, 1983). While direct retinal projections to the region of the pretectum have been observed (Benevento et al., 1977; Hendrickson et al., 1970), the response properties of neurons in this area have not been studied in the monkey. Identification of the neural circuits critical for OKN in the monkey could be facilitated by the use of short-term MD animals. The response properties of neurons mediating $\mathrm{OKN}$ and the behavior of the animals should covary when optokinetic stimuli are presented separately to the deprived and nondeprived eyes.

\section{Monocular deprivation as an animal model of amblyopia}

Long-term monocular deprivation of visual input produced by suturing 1 eyelid of rhesus monkeys does not provide a good animal model for investigation of the neural basis of amblyopia. Resulting visual deficits are much more profound than those usually observed in amblyopic patients. In our experiments, animals were behaviorally blind when vision was restricted to the deprived eye. With shorter periods of deprivation and later onsets, deficits are still severe (Harwerth et al., 1981).

Short-term monocular deprivation is a more promising model. When the amblyopic eye of patients is viewing, N/T stimulation does not elicit optokinetic responses; slow-phase velocity is reduced with T/N stimulation (Schor, 1983). We observed similar deficits in monkeys with 1 eyelid sutured for 7 or $14 \mathrm{~d}$ 
shortly after birth. Future papers will explore further the adequacy of short-term monocular deprivation as a model for studying amblyopia.

\section{References}

Baker, F. H., P. Grigg, and G. K. von Noorden (1974) Effects of visual deprivation and strabismus on the response of neurons in the visual cortex of the monkey, including studies on the striate and prestriate cortex in the normal animal. Brain Res. 66: 185-208.

Benevento, L. A., M. Rezak, and R. Santos-Anderson (1977) An autoradiographic study of the projections of the pretectum in the rhesus monkey (Macaca mulatta): Evidence for sensorimotor links to the thalamus and oculomotor nuclei. Brain Res. 127: 197-218.

Blakemore, C., F. Vital-Durand, and L. Garey (1981) Recovery from monocular deprivation in the monkey. I. Reversal of physiological effects in the visual cortex. Proc. R. Soc. London [Biol.] 213: 399_ 423.

Boltz, R. L., R. S. Harwerth, and E. L. Smith (1979) Orientation anisotropy of visual stimuli in rhesus monkey: $A$ behavior study. Science 205: 511-513.

Ciuffreda, K. J., R. V. Kenyon, and L. Stark (1978) Increased saccadic latencies in amblyopic eyes. Invest. Ophthalmol. Vis. Sci. 17: 697702.

Ciuffreda, K. J., R. V. Kenyon, and L. Stark (1979) Abnormal saccadic substitution during small-amplitude pursuit tracking in amblyopic eyes. Invest. Opthalmol. Vis. Sci. 18: 506-515.

Ciuffreda, K. J., R. V. Kenyon, and L. Stark (1980) Increased drift in amblyopic eyes. Br. J. Ophthalmol. 64: 7-14.

Cohen, B., T. Uemura, and S. Takemori (1973) Effects of labyrinthectomy on optokinetic nystagmus (OKN) and optokinetic afternystagmus (OKAN). Equil. Res. 3: 88-93.

Cohen, B., V. Matsuo, and T. Raphan (1977) Quantitative analysis of the velocity characteristics of optokinetic nystagmus and optokinetic afternystagmus. J. Physiol. (Lond.) 270: 321-344.

Crawford, M. L. J. (1978) The visual deprivation syndrome. Ophthalmol. AAOO 85: 465-477.

Crawford, M. L. J., R. Blake, S. J. Cool, and G. K. von Noorden (1975) Physiological consequences of unilateral and bilateral eye closure in macaque monkeys: Some further observations. Brain Res. 84: 150154.

Eysel, U. T., O. J. Grusser, and K. P. Hoffmann (1979) Monocular deprivation and signal transmission by $\mathrm{X}$ - and $\mathrm{Y}$-neurons of the cat lateral geniculate nucleus. Exp. Brain Res. 34: 521-539.

Flom, M. C., D. G. Kirschen, and H. E. Bedell (1980) Control of unsteady, eccentric fixation in amblyopic eyes by auditory feedback of eye position. Invest. Ophthalmol. Vis. Sci. 19: 1371-1381.

Fuchs, A., and D. A. Robinson (1966) A method for measuring horizontal and vertical eye movement chronically in the monkey. J. Appl. Physiol. 21: 1068-1070.

Ganz, L., and M. Fitch (1968) The effect of visual deprivation on perceptual behavior. Exp. Neurol. 22: 638-660.

Gstalder, R. J., and D. G. Green (1971) Laser interferometric acuity in amblyopia. J. Pediatr. Ophthalmol. 8: 251-256.

Guillery, R. W. (1972) Binocular competition in the control of geniculate cell growth. J. Comp. Neurol. 144: 117-130.

Guillery, R. W., and D. J. Stelzner (1970) The differential effects of unilateral lid closure upon the monocular and binocular segments of the dorsal lateral geniculate nucleus in the cat. J. Comp. Neurol. 139: 413-422.

Harwerth, R. S., M. L. J. Crawford, E. L. Smith, and R. L. Boltz (1981) Behavioral studies of stimulus deprivation amblyopia in monkeys. Vision Res. 21: 779-789.

Hendrickson, A., M. E. Wilson, and M. J. Toyne (1970) The distribution of optic nerve fibers in Macaca mulatta. Brain Res. 23: 425427.

Hendrickson, A., J. Boles, and E. McLean (1977) Visual acuity and behavior of monocularly deprived monkeys after retinal lesions. Invest. Ophthalmol. Vis. Sci. 16: 469-473.

Hess, R. F. (1978) Interocular transfer in individuals with strabismic amblyopia: A cautionary note. Perception 7: 201-205.

Hess, R. F., and A. Bradley (1980) Contrast perception above threshold is only minimally impaired in human amblyopia. Nature 287: 463-464.

Hess, R. F., and E. R. Howell (1977) The threshold contrast sensitivity function in strabismic amblyopia: Evidence for a two type classification. Vision Res. 17: 1049-1055.

Hess, R. F., F. W. Campbell, and T. Greenhalgh (1978) On the nature of the neural abnormality in human amblyopia: Neural aberrations and neural sensitivity loss. Pfluegers Arch. 377: 201-207.

Hess, R. F., E. R. Howell, and J. E. Kitchin (1978) On the relationship between pattern and movement perception in strabismic amblyopia. Vision Res. 18: 375-377.

Hess, R. F., F. W. Campbell, and R. Zimmern (1980) Differences in the neural basis of human amblyopias: The effect of mean luminance. Vision Res. 20: 295-305.

Hoffmann, K. P. (1979) Optokinetic nystagmus and single-cell responses in the nucleus tracus opticus after early monocular deprivation in the cat. In Development Neurobiology of Vision, R. D. Freeman, ed., pp. 63-72, Plenum, New York.

Hoffmann, K. P. (1981) Neuronal responses related to optokinetic nystagmus in the cat's nucleus of the optic tract. In Progress in Oculomotor Research, A. Fuchs and W. Becker, eds., pp. 443-454, Elsevier-North Holland, Amsterdam.

Hoffmann, K. P. (1983) Control of the optokinetic reflex by the nucleus of the optic tract in the cat. In Spatially Oriented Behavior, A. Hein and $M$. Jeannerod, eds., pp. 135-153, Springer-Verlag, New York.

Hoffmann, K. P., and M. Cynader (1977) Functional aspects of plasticity in the visual system of adult cats after early monocular deprivation. Phil. Trans. R. Soc. Lond. Ser. B 278: 411-424

Hoffmann, K. P., and H. Hollander (1978) Physiological and morphological changes in cells of the lateral geniculate nucleus of monocularly-deprived and reverse-sutured cats. J. Comp. Neurol. 177: 145-158.

Hubel, D. H., T. N. Wiesel, and S. LeVay (1976) Functional architecture of area 17 in normal and monocularly deprived macaque monkeys. Quant. Biol. 40: 581-589.

Joseph, R., and V. A. Casagrande (1980) Visual deficits and recovery following monocular lid closure in a prosimian primate. Behav. Brain Res. 1: 165-186.

Judge, S. J., B. J. Richmond, and F. C. Chu (1980) Implantation of magnetic search coils for measurement of eye position: An improved method. Vision Res. 20: 535-538.

Keller, E. L., and W. F. Crandall (1983) Neuronal responses to optokinetic stimuli in pontine nuclei of behaving monkey. J. Neurophysiol. 49: 169-187.

Kenyon, R. V., K. J. Ciuffreda, and L. Stark (1981) Dynamic vergence eye movements in strabismus and amblyopia: Asymmetric vergence. Br. J. Ophthalmol. 65: 167-176.

Kratz, K. E., P. D. Spear, and D. C. Smith (1976) Post-critical-period reversal of effects of monocular deprivation on striate cortex cells in the cat. J. Neurophysiol. 39: 501-511.

Kratz, K. E., S. V. Webb, and S. M. Sherman (1978) Effects of early monocular lid suture upon neurons in the cat's medial interlaminar nucleus. J. Comp. Neurol. 181: 615-626.

Levi, D. M., and R. S. Harwerth (1977) Spatio-temporal interactions in anisometropic and strabismic amblyopia. Invest. Ophthalmol. Vis. Sci. 16: 90-98.

Levi, D. M., and R. S. Harwerth (1980) Contrast sensitivity in amblyopia due to stimulus deprivation. Br. J. Ophthalmol. 64: 15-20.

Levi, D. M., R. S. Harwerth, and R. E. Manny (1979) Suprathreshold spatial frequency detection and binocular interaction in strabismic and anisometropic amblyopia. Invest. Ophthalmol. Vis. Sci. 18:714 724.

Malach, R., N. P. Strong, and R. C. van Sluyters (1984) Horizontal optokinetic nystagmus in the cat: Effects of long-term monocular deprivation. Dev. Brain Res. 13: 193-205.

Manny, R. E., and D. M. Levi (1982a) Psychophysical investigations in amblyopia: Uniform field flicker. Invest. Ophthalmol. Vis. Sci. 22: 515-524.

Manny, R. E., and D. M. Levi (1982b) Psychophysical investigations of the temporal modulation sensitivity function in amblyopia: Spatiotemporal interactions. Invest. Ophthalmol. Vis. Sci. 22: 525-534.

Moran, J., and B. Gordon (1982) Long term visual deprivation in a human. Vision Res. 22: 27-36.

Precht, W. (1981) Functional organization of optokinetic pathways in mammals. In Progress in Oculomotor Research, A. F. Fuchs and W. Becker, eds., pp. 425-433, Elsevier, New York.

Rentschler, I., R. Hilz, and H. Brettel (1981) Amblyopic abnormality involves neural mechanisms concerned with movement processing. Invest. Ophthalmol. Vis. Sci. 20:695-700. 
Schor, C. (1975) A directional impairment of eye movement control in strabismus amblyopia. Invest. Ophthalmol. Vis. Sci. 14: 692697.

Schor, C. (1983) Subcortical binocular suppression affects the development of latent and optokinetic nystagmus. Am. J. Optometr. Physiol. Opt. 60: 481-502.

Schor, C., and W. Hallmark (1978) Slow control of eye position in strabismic amblyopia. Invest. Opthalmol. Vis. Sci. 17: 577-581.

Schor, C. M., and D. Levi (1980a) Direction selectivity for perceived motion in strabismic and anisometropic amblyopia. Invest. Ophthalmol. Vis. Sci. 19: 1094-1103.

Schor, C. M., and D. Levi (1980b) Disturbances of small-field horizontal and vertical optokinetic nystagmus in amblyopia. Invest. Ophthalmol. Vis. Sci. 19: 668-683.

Shatz, C. J., and M. Stryker (1978) Ocular dominance in layer IV of the cat's visual cortex and the effects of monocular deprivation. J. Physiol. (Lond.) 281: 267-283.

Sherman, S. M. (1973) Visual field defects in monocularly and binocularly deprived cats. Brain Res. 49: 25-45.

Sherman, S. M. (1974) Permanence of visual perimetry deficits in monocularly and binocularly deprived cats. Brain Res. 73: 491-501.

Sherman, S. M., and P. Spear (1982) Organization of visual pathways in normal and deprived cats. Physiol. Rev. 62: 738-855.

Sherman, S. M., K. Hoffmann, and J. Stone (1972) Loss of a specific cell type from the dorsal lateral geniculate nucleus in visually deprived cats. J. Neurophysiol. 35: 532-541.

Sherman, S. M., J. R. Wilson, and R. W. Guillery (1975) Evidence that binocular competition affects the post-natal development of $Y$-cells in the cat's lateral geniculate nucleus. Brain Res. 100: 441-444.

Singer, W. (1977) Effects of monocular deprivation on excitatory and inhibitory pathways in cat striate cortex. Brain Res. 134: 568-572.

Sireteanu, R., and M. Fronius (1981) Naso-temporal asymmetries in human amblyopia: Consequence of long-term interocular suppression.Vision Res. 21: 1055-1063.

Sireteanu, R., M. Fronius, and W. Singer (1981) Binocular interaction in the peripheral visual field of humans with strabismic and anisometropic amblyopia. Vision Res. 21: 1065-1074.

Sparks, D. L., M. R. Gurski, and T. Hickey (1982a) Effects of shortterm monocular deprivation upon oculomotor function in the rhesus monkey. Soc. Neurosci. Abstr. 8: 969.

Sparks, D. L., L. Mays, and T. Hickey (1982b) Effect of long-term monocular deprivation upon oculomotor function in the rhesus monkey. Invest. Ophthalmol. Vis. Sci. 22: 90.

Spear, P. D., A. Langsetmo, and D. C. Smith (1980) Age-rclatcd changes in effects of monocular deprivation on cat striate cortex neurons. $J$. Neurophysiol. 43: 559-580.
Van Hof-Van Duin, J. (1978) Direction preference of optokinetic responses in monocularly tested normal kittens and light deprived cats. Arch. Ital. Biol. 116: 471-477.

von Noorden, G. K., and H. Burian (1958) An electro-ophthalmographic study of the behavior of fixation of amblyopic eyes in lightand dark-adapted state: A preliminary report. Am. J. Ophthalmol. 46: 68-77.

von Noorden, G. K., and H. M. Burian (1959a) Visual acuity in normal and amblyopic patients under reduced illumination. Behavior of visual acuity with and without neutral density filter. Arch. Ophthalmol. 61: 533-535.

von Noorden, G. K., and H. M. Burian (1959b) Visual acuity in normal and amblyopic patients under reduced illumination. The visual acuity at various levels of illumination. Arch. Ophthalmol. 62: 396-399.

von Noorden, G. K., J. E. Dowling, and D. C. Ferguson (1970) Experimental amblyopia in monkeys. I. Behavioral studies of stimulus deprivation amblyopia. Arch. Ophthalmol. 84: 206-214.

Waespe, W., B. Cohen, and T. Raphan (1983) Role of the flocculus and paraflocculus in optokinetic nystagmus and visual-vestibular interactions: Effects of lesions. Exp. Brain Res. 50: 9-33.

Wesson, M. D., and M. Loop (1982) Temporal contrast sensitivity in amblyopia. Invest. Ophthalmol. Vis. Sci. 22: 98-102.

Wiesel, T. N., and D. H. Hubel (1963) Effects of visual deprivation on morphology and physiology of cells in the cat's lateral geniculate body. J. Neurophysiol. 26: 978-993.

Wiesel, T. N., and D. H. Hubel (1965) Comparison of the effects of unilateral and bilateral eye closure on cortical unit responses in kitten. J. Neurophysiol. 28: 1029-1040.

Wilson, J. R., and S. Sherman (1977) Differential effects of early monocular deprivation on binocular and monocular segments of cat striate cortex. J. Neurophysiol. 40: 892-903.

Wood, C. C., P. D. Spear, and J. Braun (1973) Direction-specific deficits in horizontal optokinetic nystagmus following removal of visual cortex in the cat. Brain Res. 60: 231-237.

Yee, R. D., R. W. Baloh, V. Honrubia, C. Lau, and H. A. Jenkins (1979) Slow build-up of optokinetic nystagmus associated with downbeat nystagmus. Invest. Ophthalmol. Vis. Sci. 18: 211-216.

Zee, D. S., R. D. Yee, and D. A. Robinson (1976) Optokinetic responses in labyrinthine-defective human beings. Brain Res. 113:423428.

Zee, D. S., A. Yamazaki, P. Butler, and G. Gucer (1981) Effects of ablation of flocculus and paraflocculus on eye movements in primate. J. Neurophysiol. 46: 878-899.

Zctlan, S. R., P. D. Spear, and E. E. Geisert (1981) The role of cortico-geniculate projections in the loss of Y-cells in monocularly deprived cats. Vision Res. 21: 1035-1039. 